\title{
THE USE OF LIGHT AIRCRAFT IN EAST AFRICAN WILD LIFE RESEARCH AND GAME MANAGEMENT
}

\author{
By D. R. P. ZA Phiro \\ Game Warden, Kajiado District, Kenya Game Department \\ and \\ LEe M. TALBot
}

Ecologist, Wild Life Research Project, sponsored jointly by United States National Academy of Sciences, National Research Council, Government of Kenya, and New York Zoological Society

Most of the wild life management and research problems in East Africa to-day are concerned with widespread populations of varied species of animals distributed over vast areas of usually roadless terrain. In such conditions it is difficult, uneconomic and time consuming to operate entirely from the ground, and a light aircraft, correctly used, can be of great value.

The authors have used light aircraft in connection with game work in East Africa and elsewhere for over ten years. This paper summarizes our findings on the uses of light aircraft in wild life research and in applied game management in East Africa.

We wish to express our appreciation to the Kenya Game Department, under whose auspices this work has been accomplished, and to Mr. D. R. M. Stewart, Game Department biologist, for editing the manuscript.

\section{History}

Light aircraft have been used sporadically in various phases of fish and game work in the United States at least since the 1930 's and some of the earliest systematic wild life research in which light aeroplanes were used came from North American studies of single species of large animals, especially deer, antelope, elk and moose (Bannfield et al., 1955; de Vos and Armstrong, 1954 ; Edwards, 1954, ; Matteson, 1950 ; Robel, 1960).

In East Africa probably the first systematic long-term use of a light aircraft in wild life management has been by $\mathbf{D}$. Zaphiro who since 1953 has used a light aircraft almost daily in wild life work. This undertaking has involved the regular plotting of movements and distribution of animal populations with quarterly censuses of the most numerous species of the wild life in the principle game areas of Kajiado District, Kenya (Zaphiro, 1959). In January and February, 1956, L. Talbot used light 
aircraft to locate game herds, follow their movements, and survey ground conditions in connection with an ecological reconnaissance of the Serengeti National Park, Tanganyika (Talbot, 1956). Small planes have been used in Uganda since late 1956, by the American wild life specialists in connection with the Uganda Fulbright Wild Life Research Projects (Buechner, 1957, 1958a, 1958b ; Longhurst, 1957a, 1957b), and by a Uganda Game Warden (Newton, R. F., 1958). In 1957 one of the Fulbright specialists, Dr. H. Buechner, made an aerial census of the elephants in Tsavo National Park, Kenya (Buechner, 1957). In 1958 Dr. B. Grzimek and M. Grzimek also used a light aeroplane to census the animals of the Serengeti National Park, Tanganyika (Grzimek and Grzimek, 1960). In the same year, two aerial censuses of the wild life of the Mara Plains, Kenya, were carried out as a part of Dr. F. Darling's ecological reconnaissance of that area (Darling, 1960). Since 1959, Zaphiro and Talbot have used light aircraft for census, population structure analysis, and distribution and movement determination of wild life; and for vegetational and ecological surveys of the northern Serengeti, Tanganyika, and portions of Narok and Kajiado Districts of Kenya (Zaphiro, 1954-1961 ; Talbot, 1960b).

\section{Type of Aircraft}

\section{General Considerations}

The authors have used a variety of light aircraft for wild life work in conditions ranging from the American Arctic to tropical Africa. In the initial stages experience was gained in any aircraft that was available. The combined experience of both authors has revealed the advantages and disadvantages of various designs of aircraft in work of this kind. They believe that much of the lack of enthusiasm displayed by persons with a minimum of experience with aircraft in wild life work can be traced to their use of types of aircraft unsuited to such work.

In presenting the essential characteristics of the aircraft used, it is useful first to consider the requirements of the work involved. In this work the aircraft serves primarily as a mobile elevated observation platform. The first consideration, therefore, must be one of visibility. This consideration eliminates all low-wing aircraft. It also eliminates aircraft where forward visibility and visibility on both sides of the observer are obstructed. Although there are situations where it is desirable to carry more than two observers, in most circumstances we have found aerial wild life work more satisfactorily and accurately pursued with two 
observers in a tandem two-seater aircraft, with one of the observers also acting as pilot.

The second aspect of visibility is speed. Accuracy of observation usually depends on the duration of observation. Therefore it is essential in using a fixed-wing aircraft that it should be capable of flying safely at very low speeds, while at the same time maintaining complete control with over-the-nose visibility. At low speeds an aircraft must, in order to maintain altitude, fly in a nose-high attitude. This eliminates aircraft with a cowling design which blocks the forward view of the pilot when flying at minimum speeds.

The third factor concerning visibility is the distance between the observer and the objects under observation. Flights at low altitudes are frequently necessary in wild life work. Therefore it is essential to have an aircraft with sufficient power to gain altitude quickly in an emergency. An aircraft with a high power-to-weight ratio is also essential to enable short take-offs and steep climbs out of the often limited landing spaces available.

Flight characteristics and stability vary greatly between different types of aircraft. Where the pilot also acts as observer, his attention is necessarily diverted. Therefore it is most important that an aircraft is used with a flight behaviour at slow speeds which is both stable and predictable, in order to allow the pilot maximum concentration on observation elsewhere.

\section{Cost}

A number of light aircraft of varying price ranges will meet the above criteria, although the choice may be restricted by the fact that the initial cost and operating expenses have to be related to the financial means available. Economy is usually a prime consideration in wild life work. The operating costs of aircraft with three or more seats are significantly higher than those of a two-seater. The relatively inexpensive, ultra light, high-powered two-seater has proved itself well suited for the wild life work undertaken by the authors. Most of the more successful aerial wild life work in East Africa has been accomplished in D. Zaphiro's Piper Cub Special P.A.11. This is a tandem, two-seater with a 90 horse power engine which has flight characteristics and reserves of power particularly well suited to this work.

The initial capital outlay of a totally rebuilt aeroplane such as the Piper Cub Special is no greater than that for a new 
three-ton lorry. The only limit to its useful life is the decision that may eventually be made by its manufacturers to stop production of spare parts. Since this type of aeroplane is in wide demand throughout much of the world its future is considered safely assured.

Unlike a motor vehicle which depreciates rapidly in two or three years, a light aeroplane can be safely used for ten, twenty, or even more years. If well maintained and carefully looked after it suffers little depreciation in value. The aeroplane used by the authors in the past two and a half years is, in fact, valued to-day at very nearly twice its original purchase price in 1949 .

The cost of running a light aircraft of this kind in East Africa, inclusive of maintainance, insurance, fuel, licensing, and flight fees is approximately $9 d$. a mile. In comparison, the all-inclusive cost of running a land-rover in East Africa is approximately Shs 2/50 a mile for the first 30,000 miles. Beyond that mileage the cost rapidly increases. If the vehicle is used for much cross-country work the initial figure may be increased also.

\section{Personnel}

Aerial wild life work requires a high degree of concentration. To achieve maximum results with maximum safety the following considerations are important :-

(a) Confidence.-The pilot and observer must have confidence in the aircraft and in each other. Only by working together continually can this be achieved.

(b) Flying experience.-The piloting of an aircraft involved in wild life work is particularly exacting. In addition to flying the aeroplane the pilot is also required to act as an observer. To accomplish this with any degree of safety, while concentrating elsewhere, it is essential that the pilot has sufficient flying experience for the mechanics of safe flight to have become part of his second nature. Work of this kind may involve flying over unfamiliar territory, in difficult conditions and occasionally landing in areas not previously reconnoitered from the ground. If these potentially dangerous activities are not undertaken with caution, common sense and a full sense of responsibility, the results may be fatal.

(c) Experience in aerial observation.-Accurate, rapid observation from an aircraft is very different from similar work undertaken from ground level. Maximum accuracy of observation from aircraft requires experience in this type of work, and the techniques used must be adapted to each new set of conditions. 


\section{Application}

\section{Aerial Game Counts}

Since 1954 aerial game census has been a regular part of the activities of the Kenya Game Department. Most of the earlier work involved areas where complaints had been made by the local authorities of excess numbers of game competing with livestock in newly formed grazing schemes. As no complete prior counts existed, Game Department action had previously been forced to rely on the often grossly exaggerated claims of the complainants or of the administration. Starting in 1954 census flights were made, using as observers various Administrative officers. Without exception these flights proved that the numbers of wild animals involved were far less than had been estimated by those making the complaints (Peacock, 1955). Since the local Administrative representatives or other local authorities involved had helped to make the counts, these census figures were accepted.

Much of this early work was financed privately by the owner of the plane (D. Zaphiro) in an attempt to achieve Government recognition of the value of aircraft in Game Department work. By 1960 this value was firmly established, and in that year funds were allocated specifically to extend the aerial work throughout the game areas of Kenya.

In addition to the work already established in Kajiado District this involved seven aerial census operations in four other districts (Grimwood, I., 1960 ; Zaphiro, D. R. P., 1960 $a, b, c)$.

\section{Aerial Analysis of Age and Sex Structures of Wild Life Populations}

Although knowledge of the total numbers of animals in wild life populations is important, it is often of equal or greater importance to know the population structure-the age and sex ratios. Controlled experiments carried out by the authors in 1960 showed that this work could be carried out from the air under East African conditions with greater efficiency, accuracy and economy than from the ground. The details of these experiments are presented in a separate paper (Talbot and Zaphiro, 1961).

\section{Locating and Following Marked Animals}

The best method of following animal movements and determining social structure of animal populations is to make use of 
marked animals. For the present study, two adult male wildebeest were captured, moved six to ten miles to the base camp, marked and released. The captures were affected by means of an air pistol and flying syringe (Talbot, 1960a). The animals were marked by painting the horns, bobbing the tails, ear tagging with plastic sheets roughly $2 \frac{1}{2}$ by $3 \frac{1}{2}$ inches and painting $1 \mathrm{ft}$. square patches on their backs. During the subsequent two week period of daily aerial observation, these animals were easily located and observed amongst 2,000 other wildebeest, although in this time they had moved about fifteen miles. At the end of this period the paint was beginning to wear off, but the bobbed tail and ear tags showed clearly from an altitude of 1,000 feet, and when painted, the animals remained distinguishable from 2,000 feet.

\section{Locating Sick Animals}

During the course of epidemics affecting game it is often necessary to collect and analyse specimens from sick or dying animals. Except in extreme epidemics, suitable specimens are usually difficult to find from the ground, since they are often widely dispersed. There is also a need for urgency, since dying or freshly dead individuals are disposed of very quickly by scavengers. We have used a small plane to locate sick animals of several species and to plot the most feasible ground approach route, as well as to assess the extent of the epidemic. One such example was a rinderpest epidemic in January, 1960, among buffalo along the Southern Uaso Nyiro River north of Lake Natron. Although several hundred animals were sick or dying, a day's search by land-rover usually resulted in finding only one or two carcasses. In contrast, by using the aircraft for twenty minutes reconnaissance flight at dawn, then following up by land-rover, four or more animals could be examined in a morning. Furthermore, when sick or dead animals have been observed by plane in remote areas it has often been possible to land close by and examine the animals immediately.

\section{Location of Game Concentrations for Ground Study}

In areas such as the Athi-Kapiti Plains and Mara-Loita regions of Kenya, and the Serengeti region of Tanganyika, herds of wildebeest, zebra and other animals move long distances in quite short periods. Where intensive ground study of such herds is required, a light plane can be a most valuable aid in locating the concentrations and following their movements. 
In the Mara-Loita region, for example, to find game concentrations preparatory to ground study often requires driving at least 650 miles, much of it cross-country, which takes at least three and a half days. At Shs 3/-per mile, this reconnaissance costs Shs 1,950, plus the salaries for three and a half days of one or two observers. Using a light aircraft the same area can be covered in about three hours. This aerial reconnaissance costs Shs 225, plus three hours' salaries, and the remaining three and a quarter days saved may be applied to study rather than to travel and search.

A further important aspect of the use of an aeroplane, particularly where counting is involved, is that it is often important to count the animals concerned in the shortest possible time. Loss of accuracy may otherwise occur because of the movement of the animals.

\section{Aerial Reconnaissance of Land Conditions}

An aircraft can be used both for initial orientation and, after subsequent detailed ground study, for large-scale plotting of ecological factors. Aircraft have been used extensively in ecological land use surveys in Kenya Masailand (Talbot, 1960b). They have also been found invaluable in demonstrating land misuse to persons who had previously been unable to appreciate it fully from the ground.

\section{Use in Other Game Management Duties}

The light plane has been found extremely effective against poachers. By flying low it has been found possible to identify the vehicle and to read its registration number, and even on occasion to identify the individual. Other poachers have been located by plane, and subsequently apprehended either by the pilot or by additional personnel working on the ground. Poachers' hides, pits, snare lines and nets are often seen more readily from the air than from the ground.

Illegal grazing in parks, reserves, or grazing schemes, is sometimes extremely difficult to detect from the ground, but can be quickly spotted from the air.

The aircraft aids game control in three ways. Where game animals conflict with human interests they can often be quickly and effectively moved either by judicious bombing with thunder flashes or by aerial herding. Normal control measures in connection with crop protection, etc., can be facilitated by rapid and efficient location of the animals from the air. 
Valuable game trophies, such as ivory and rhino horns, have been located from the air, and subsequently recovered by ground staff of the National Parks (Sheldrick, 1957).

For the past six years, D. Zaphiro has used a light plane in addition to ground transport in carrying out routine Game Department duties. In addition to the operations detailed above, these have included transport of equipment and staff, seeding of fish in fresh water lakes, recovery of stolen cattle, mapping and the location of grass fires.

\section{Discussion}

\section{Advantages}

The advantages gained from the use of light aircraft in wild life research include greater efficiency and economy in animal counting, animal population analysis, location and movement plotting and other activities based on observation of animals, vegetation patterns and land conditions. These advantages are especially pronounced where the land areas involved are large and ground travel difficult, as in most of East Africa. The use of aircraft in such work also provides a perspective for observation of conditions, movements and landscape which cannot be gained from the ground.

In applied game management a light aircraft greatly increases the effectiveness of a game or parks warden, by enabling him to survey rapidly a large area, to observe conditions or activities throughout the area, and to visit and land at remote areas accessible from the ground only after hours or days of expensive, arduous travel. We do not imply however, that ground work is not still essential, but rather that the aeroplane cuts out much unproductive travelling on the ground, and assists and improves upon many of the methods hitherto used.

\section{Limitations}

Limitations are imposed by visibility, i.e. it is more difficult, though not impossible, to observe wild life under dense bush or forest. Certain light conditions, especially at noon when the sun is high, also reduce the effectiveness of observation.

Weather may limit the use of a light aircraft, although in East Africa wet weather provides more of a limitation to work on the ground than in the air.

Close and detailed observation is obviously made more difficult by the fact that a fixed-wing aircraft is constantly in motion. 


\section{SUMmary}

This paper is based on the authors' ten years' experience with light aircraft in wild life work. It summarizes our findings on the uses of light aircraft in wild life research and in game management, applied to East African conditions.

The type of aircraft that has proved most satisfactory for this work is a light weight, high wing, tandem two-seater, monoplane with relatively low initial cost and operating expenses, and stable, predictable flight characteristics at very low speeds. As both the flying and observation are extremely exacting; to achieve accuracy, efficiency and safety the pilot and observer must have considerable experience in the work and confidence in each other.

Light aircraft have been used in East African wild life work with some regularity for about six years. Operations in which they have been used effectively include animal counts ; animal population structure analysis; distribution and movement plotting ; location of herds for ground study ; location and examination of sick animals; location and observation of marked animals; ecological reconnaissance; anti-poaching operations; game control operations and a variety of other routine game management duties.

When the techniques for the aircraft's use are based on detailed ground studies, and when it is used as a tool in conjunction with ground research or management operations, by observers familiar with the ecology of the animals and area, a light aircraft can increase substantially accuracy, efficiency and economy in wild life research and game management.

\section{LITERATURE CITED}

Bannfield, A., Flook, D., Kelsal,, J., and Loughrey, A., 1955. An aerial survey technique for northern big game. Trans. N. Amer. Wildl. Conf., 20.

Buechner, H. K., 1957. Aerial count of elephant in Tsavo National Park. Kenya Game Department file GA 3/1/1.

- 1957-8. Progress reports to Uganda Ministry of Natural Resources on Fulbright Wildlife Research Projeets. Mimeo. Kenya Game Department file GA $3 / 6 / 5 / 1$.

1958a. Elephant census 11. Uganda Wildlife and Sport, 1 (4), 17-25.

dE Vos, A., and Armstrong, G. E., 1954. Aerial census of moose at Black Bay Peninsula, Ontario. Ontario Dept. Land and For., Tech. Bull. Fish and Wildl., Ser. No. 3.

Edwards, R. 'T., 1954. Comparison of an aerial and ground census of moose. J. Wildl. Mgmt., 18.

Darling, F. F., 1960. An ecological reconnaissance of the Mara Plains in Kenya Colony. Wildl. Monographs, No. 5.

Grimwood, I., 1960. Report of an aerial count of game in the Loita Plains. Kenya Game Department, typed report, ref. GA 3/1/8/8. 
Grzimek, M., and Grzimer, B., 1960. Census of plains animals in the Serengeti National Park, Tanganyika. J. Wildl. Mgmt., 24 (1), $27-37$.

Longhurst, W., 1957a. Elephant census 1. Uganda Wildlife and Sport, 1.

1957b. Fulbright progress report No. 1. Kenya Game Department file GA 3/6/5/1.

Matteson, C. P., 1950. An evaluation report of airplane use in North American game and fish management. Colorado Game and Fish Commission Current Report No. 27, pp. 1-41.

Newton, R. F., 1958. Elephant census. Uganda Wildlife and Sport, 1 (3), 28-30.

Peacock, R. T., 1955. Flight over Athi River and Kajiado Area, Thursday, 14th July. Kenya Game Department file GA 3/1/8/8.

Rosel, R. J., 1960. Determining elk through periodic aerial counts. J. Wildl. Mgmt., 24 (1), 103-4.

Sheldrick, D., 195\%. Correspondence on Kenya Game Department file GA $3 / 2 / 3 / 6$.

Talbot, Lee M., 1956. Serengeti National Park Report. International Union for the Prot. of Nature, Brussels : and National Parks Assn., Washington D.C.

1960a. Field immobilization of some East African wild animals and cattle. E. Afr. Agric. For. J., 26 (2), 92-102.

1960b. Land use survey of Narok District, Kenya. District Administration, Narok. Mimeo.

and ZaPhiro, D. R. P., 1961. Aerial Analysis of wild life population structures. Conference on Land Use Problems in areas containing game, Lake Manyara, Tanganyika. Mimeo.

Zaphiro, D. R. P., 1959. The use of a light aircraft to count game. Wild Life, 1 (31), Nairobi, Kenya.

1960a. Aerial census of game-Samburu, May, 1960. Kenya Game Department, typed report, ref. GA 3/1/8/8.

1960 b. Report on Mara counts. Kenya Game Department, typed reports, ref. GA 3/1/8/8.

1960c. Aerial census of game-Samburu, September. Kenya Game Department, typed report, ref. GA 3/1/8/8.

1954-1961. Monthly Game Reports. Kajiado District Monthly Game Reports. Typed. Kenya Game Department, Nairobi, ref. GA 3/5/6. 